\title{
A Comprehensive Study for the Pharmacological Activities of Mercurius Solubilis
}

\section{Simranjeet Kaur*}

Faculty of Pharmaceutical Sciences, PCTE Group of Institutes, Ludhiana, Punjab, India

*Corresponding Author: Simranjeet Kaur, Faculty of Pharmaceutical Sciences, PCTE Group of Institutes, Ludhiana, Punjab, India.
Received: May 16, 2021

Published: June 23, 2021

(C) All rights are reserved by Simranjeet Kaur.

\begin{abstract}
At room temperature, mercury is a silver- colored metallic element in fluid form. Organic and inorganic mercury salts are used as antiseptic, preservative, vaccine, etc. exposure of various mammalian species to mercurial compounds can give rise to immunosuppression and auto- immunity. Merc solubilis is of mineral origin. Mercurius solubilis, is prepared from mercury nitrate, $\mathrm{Hg}_{(\mathrm{NO}} \mathrm{N}_{2}$. This medicine is used clinically in homeopathy for the treatment of infectious and suppurative processes. Mercurius solubilis is also used for treatment of various acute and chronic inflammatory conditions by homeopathic physicians. It is also called as Quicksilver. Mercurius solubilis is considered as a best alternative drug for acute inflammatory conditions treatment.
\end{abstract}

Keywords: Mercurius Solubilis; Mercury; Nervous System

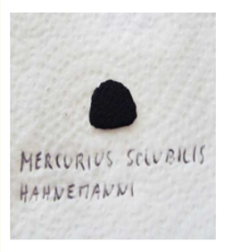

\begin{tabular}{|c|c|}
\hline Remedy Name & Common Name \\
\hline Merc. Sol. Mercury solution & Quicksilver, Mercurius solubilis \\
\hline
\end{tabular}

Figure 1

\section{Introduction}

At room temperature, mercury is a silver- colored metallic element in fluid form. Organic and inorganic mercury salts are used as antiseptic, preservative, vaccine, etc. exposure of various mammalian species to mercurial compounds can give rise to immunosuppression and auto- immunity. Merc solubilis is of mineral origin.
Mercurius solubilis, is prepared from mercury nitrate, $\mathrm{Hg}\left(\mathrm{NO}_{3}\right)_{2}$. This medicine is used clinically in homeopathy for the treatment of infectious and suppurative processes. Mercurius solubilis is also used for treatment of various acute and chronic inflammatory conditions by homeopathic physicians. It is also called as Quicksilver. Mercurius solubilis is considered as a best alternative drug for acute inflammatory conditions treatment.

Mercury is extracted from cinnabar ore (mineral origin), which is found in volcanic rocks [1]. Commercially it is extracted for a variety of industrial purposes. Mercury is used in thermometers and was at one stage a major ingredient in tooth fillings.

Mercury is a general poison having affinity with a wide range of tissues, notably mucous membranes, bones, salivary glands, lymph nodes, liver, kidneys, nervous system, blood and skin. Medicinally, mercury was not used before fifteen century, while the ammonium nitrate salt of mercury that was introduced by Hahnemann into 


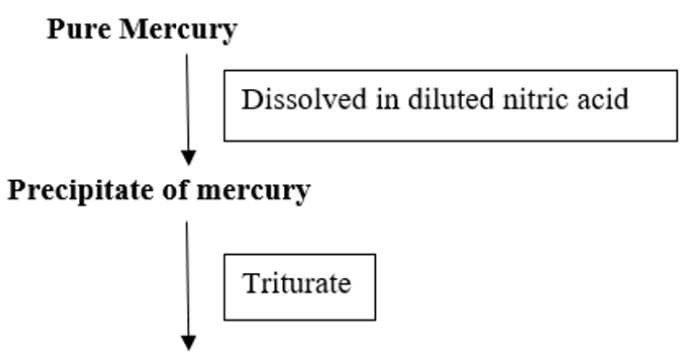

Soluble Mother Tincture

Figure 2

medicine in 1788 was called as Mercurius solubilis, that is also
Remedy preparation

Profile

- Used for conditions that cause excessive bodily secretions that are foul smelling, high fever and extreme perspiration.

- Swollen glands, excessive salivating, abscesses and ulcers may also be present.

- Symptoms tend to be worse at night and patients are very sensitive to cold or heat, so the moderate conditions are essential for recovery.

- Excessive salivation is the common symptom, as is constant swallowing and dribbling on the pillow at night [3].

Merc sol centesimal high dilutions $(\mathrm{CH})$ and equivalent concentrations are described below [4]

called as Mercurius oxydulatus niger [2].

\begin{tabular}{|l|c|c|c|c|}
\hline Concentration(mg/ml) & Merc sol 6 CH & Merc sol 12 CH & Merc sol 30 CH & Merc sol 200 CH \\
\hline Merc sol & $10^{-15}$ & $10^{-27}$ & $10^{-63}$ & $10^{-403}$ \\
Hg & $8.21 \times 10^{-16}$ & $8.21 \times 10^{-28}$ & $8.21 \times 10^{-64}$ & $8.21 \times 10^{-404}$ \\
\hline
\end{tabular}

Table 1

\section{Reported activities of mercurius solubilis}

There are many pharmacological activities of umbelliferone which are described in literature as reported by many researchers. These reported activities includes: Anti- inflammatory activity, anti leprotic activity [6], Role in immunomodulation [4], bacteriological response in alveolitis process in rats [7], Gingivitis gravidica [8], protective effect on genotoxic effects of mercurius chloride [9].

\section{Anti- inflammatory activity}

Inflammation is a local response of the living mammalian tissues to the injury, and it is a body defence reaction in order to eliminate the extend of injurious agents. Already used drugs for their anti-inflammatory activity are narcotics e.g. opioids or nonnarcotics e.g. salicylates and corticosteroids e.g. hydrocortisone, but all of these possess side- effects mercurius solubilis possesses significant anti-inflammatory activity by following the mechanism.

\section{Leprosy}

Leprosy is a chronic infectious disease caused by Mycobacterium leprae and affects the peripheral nerves and leads to im-

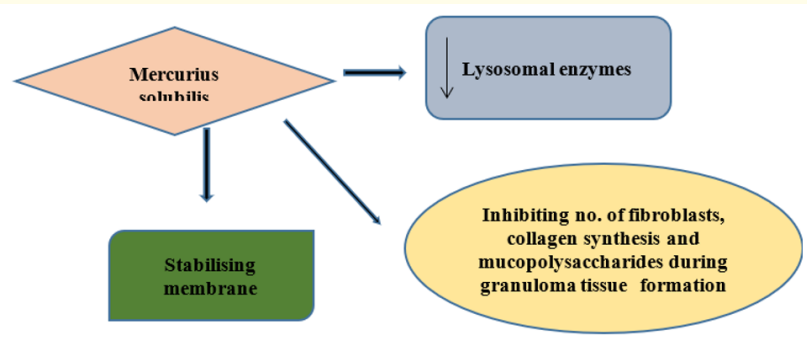

Figure 3: Mercurius as anti- inflammatory agent [5] (Vangoory,

$$
\text { Y., et al. 2013). }
$$

pairment of motor, sensory or autonomic function [6]. Out of the drugs being included in MDT Dapsone, and clofazemine, both are bacteriostatic in nature, due to which the affected person does not get rid of the residual effects of the disease and dapsone has also been found to lower the CMI status of patients $[10,11]$. However, 
Rifampicin is known to kill $99.9 \%$ of M. leprae within a month's time, instead of this, Relapses are not uncommon in these cases. Mercurius solubilis is found to save the patients from the serious consequences impairment in nerve function and the development of deformity [6]. A borderline leprosy case treated with Merc. Solubilis for 2 years, patient show improvement in signs and symptoms [12].

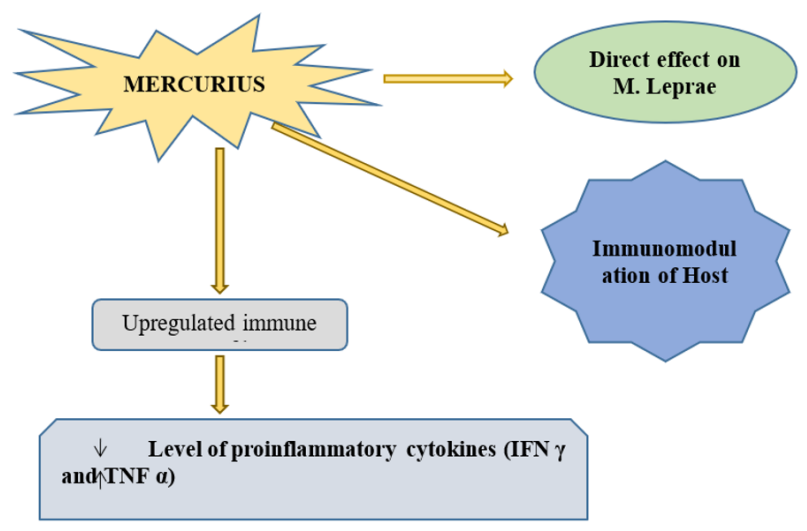

Figure 4: Mercurius as antileprotic agent (Chakraborty, D., et al. 2015).

\section{Role in Immunomodulation}

Macrophages are among the first cells to interact with foreign or abnormal host cells and their products, by virtue of their presence at the portals of entry. Depending upon the recognition receptor and the stages of differentiation, they release various products, including cytokines that mobilize and influence other resident cells in tissues and reactive oxygen species that participate in bacterial killing and are drawn in inflammation and tissue injury. Macrophages also present antigens to $\mathrm{T}$ and B- Lymphocytes. Macrophages have a central role in immunomodulation, by participating in mobilization, activation and regulation of all immune system [4].

Mercurius solubilis has been shown to alter macrophages function, by increasing the production of IL- 4 , IFN- $\gamma, \mathrm{NO}, \mathrm{H}_{2} \mathrm{O}_{2}$ and probably $\mathrm{ONOO}^{-4}$.

\section{Bacteriological process in alveolitis}

Alveolitis condition may develop subsequent to the extraction of tooth, it may be due to the presence of various species of pyrogenic
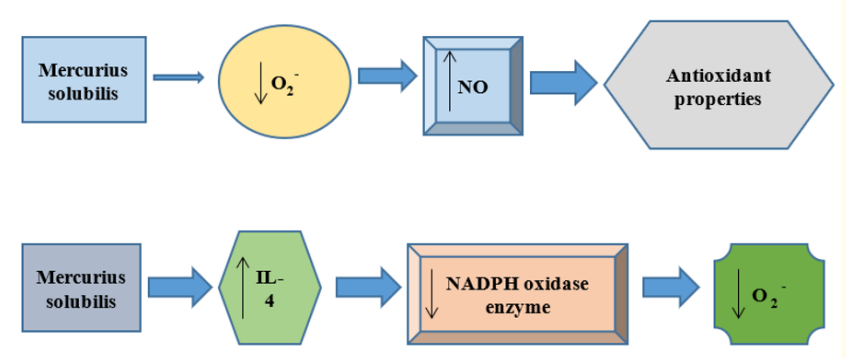

Figure 5: Mechanism of action of mercurius on macrophages.

bacteria. Alveolitis condition is accompanied by symptoms like pain, fetid odour, exposed alveolar bone, absence of tissue healing, purulent secretion, edema, lymphoadenopathy and hyperemia [7].

In the infectious process there was a decrease in gram- positive and an increase in the gram- negative bacteria. Local or systemic antibiotics were most commonly being used to treat alveolitis, but their numerous use may lead to the bacterial resistance. Homeopathic drugs are being more advantageous due to shorter duration of symptoms, lower cost and fewer side effects. Mercurius solubilis do not decrease the bacterial growth, but the microbiota is maintained.

Antibiotics bacterial resistance

Mercurius solubilis reduces the duration of symptoms, cost as well as the adverse effects [7].

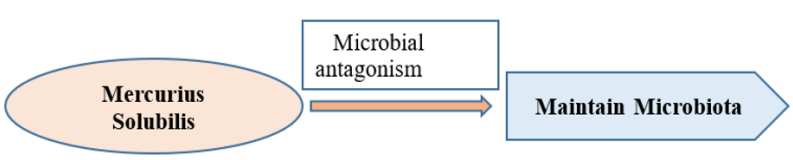

Figure 6: Mechanism of action of mercurius solubilis on alveolitis [7].

\section{Gingivitis gravidica}

Usual symptoms of gingivitis are- tendency to bleed, colour, texture, shape, size, consistency and position. Mercurius solubilis $6 \mathrm{x}$ is found to give a curative effect in the disease. 


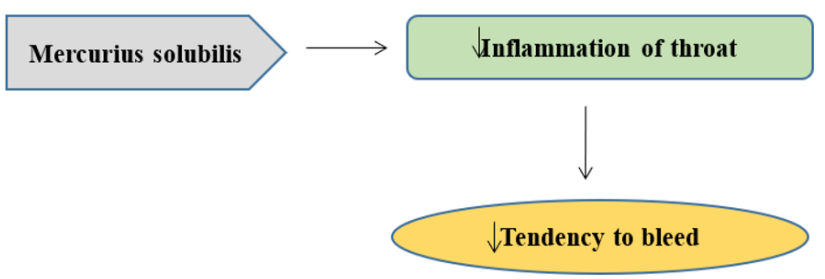

Figure 7: Action of mercurius on Gingivitis [8].

Mercurius solubilis action on genotoxic effects of mercuric chloride

Mercurius chloride is an tremendously toxic salt and have tendency to cause chromosomal aberrations (damaging effect), micronuclei in the bone marrow cells (small chromatin- containing bodies arising from the chromosomes that failed to incorporate into daughter nuclei following mitosis) and increased frequencies of sperm head abnormality.
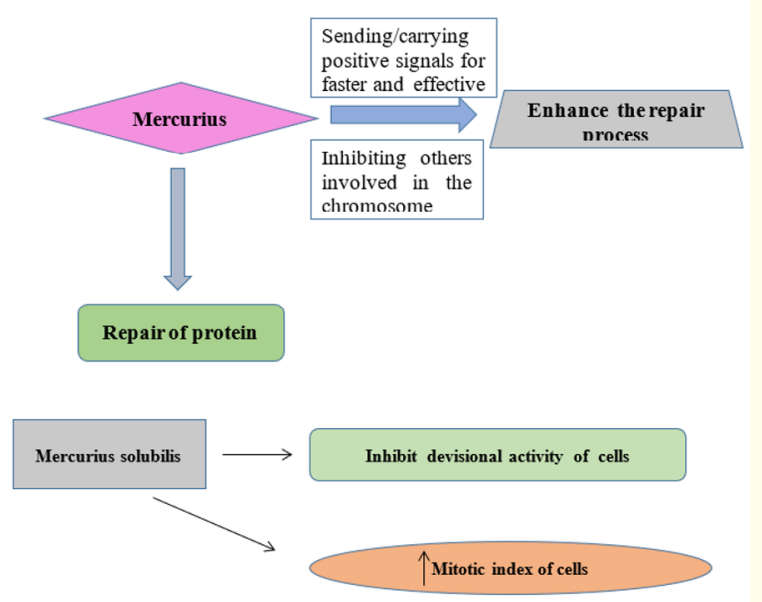

Figure 8: Mechanism of action of mercurius to protect from genotoxic effects of mercuric chloride [9].

\section{Mercurius solubilis action on memory}

Merc sol 30X have strong nitric oxide scavenging activity and it also works against free radicals. Therefore, it shows antiamnesic activity.

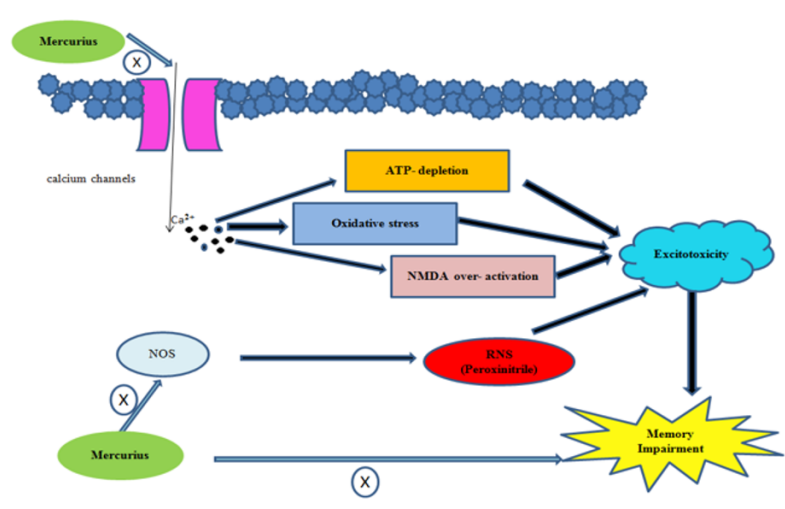

Figure 9: Action of mercurius on memory deficits [13].

Mercurius solubilis effect on Cerebral blood flow and memory

Merc. Sol provides memory impairment protection because of it Cerebral blood flow potentiation effect. Moreover, due to its antiinflammatory property it shows neuroprotection.

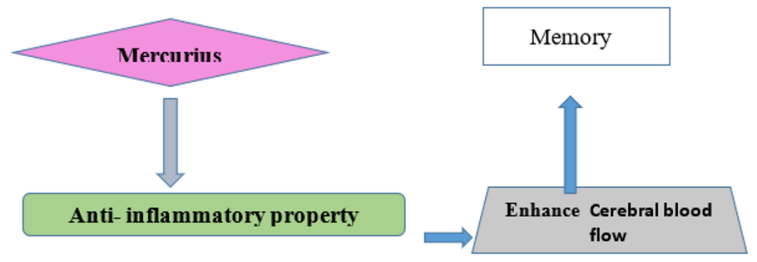

Figure 10: Action of mercurius on cerebral blood flow and memory [14].

\section{Conclusion}

Because of its effect on several parameters including lymphocyte count, cerebral blood flow, nitric oxide scavenging and many other activities, it shows its pharmacological effects.

\section{Bibliography}

1. Lockie A. "Encyclopedia of homeopathy". New York: Dk Pub (2006): 7. 
2. Gibson D. "Mercurius, a study". British Homeopathic Journal 56.1 (1967): 30-33.

3. Lockie A. "Encyclopedia of homeopathy". New York: Dk Pub; 15 (2006).

4. de Oliveira S., et al. "Mercurius solubilis: actions on macrophages". Homeopathy 100.4 (2011): 228-236.

5. Y Vangoori., et al. "Anti-inflammatory profile of mercurius solubilis". International Journal of Pharmaceutical Sciences Invention 2.8 (2013): 22-25.

6. Chakraborty D., et al. "Therapeutic effect of Mercurius solubilis on immune status of a borderline leprosy case". Indian Journal of Research in Homoeopathy 8.2 (2014): 100.

7. de Araújo F., et al. "Effect of Mercurius solubilis on the bacteriological response in the alveolitis process in rats". Homeopathy 98.3 (2009): 160-164.

8. Monterde-Coronel M., et al. "The efficacy of mercurius solubilis, a homeopathic medication, for the treatment of periodontal disease". Allgemeine Homöopathische Zeitung 262.2 (2017): 2-76.

9. Datta S., et al. "Comparative Efficacy of Pre-feeding, Post-feeding and Combined Pre- and Post-feeding of Two Microdoses of a Potentized Homeopathic Drug, Mercurius Solubilis, in Ameliorating Genotoxic Effects Produced by Mercuric Chloride in Mice". Evidence-Based Complementary and Alternative Medicine 1.3 (2014): 291-300.

10. SHETTY V., et al. "A high incidence of viable Mycobacterium lepraein post-MDT recurrent lesions in tuberculoid leprosy patients". Leprosy Review 72.3 (2001).

11. "Mercurius solubilis bei COVID-19". Allgemeine Homöopathische Zeitung 266.1 (2014): 5.

12. Zdanov A. "Structural Features of the Interleukin-10 Family of Cytokines". Current Pharmaceutical Design 10.31 (2004): 3873-3884.

13. S Kaur., et al. "Mercurius solubilis attenuates scopolamine-induced memory deficits and enhances the motor coordination in mice". International Journal of Neuroscience 128.3 (2017): 219-230.

14. Shukla R., et al. "Homoeopathic medicine Mercurius solubilis treatment improves cerebral blood flow and memory in experimentally induced Dementia in rats". Indian Journal of Research in Homoeopathy 11.1 (2017): 58.

Volume 4 Issue 7 July 2021

(C) All rights are reserved by Simranjeet Kaur., et al. 